Review

\title{
Microfluidic Systems for Isolation of Spermatozoa from Testicular Specimens of Non-Obstructive Azoospermic Men: Does/Can It Improve Sperm Yield?
}

\author{
Gary D. Smith ${ }^{1, *}$, Clementina Cantatore ${ }^{2}$ and Dana A. Ohl ${ }^{3}$ \\ 1 Reproductive Sciences Program, Departments of Obstetrics/Gynecology, Physiology, and Urology, \\ University of Michigan, Ann Arbor, MI 48103, USA \\ 2 Reproductive and IVF Unit, Department of Maternal and Child Health, Asi Bari, \\ 70014 Conversano (BA), Italy; clemecant@yahoo.it \\ 3 Department of Urology, University of Michigan, Ann Arbor, MI 48103, USA; daohl@med.umich.edu \\ * Correspondence: smithgd@umich.edu; Tel.: +1-734-764-4134
}

check for updates

Citation: Smith, G.D.; Cantatore, C.; Ohl, D.A. Microfluidic Systems for Isolation of Spermatozoa from

Testicular Specimens of

Non-Obstructive Azoospermic Men: Does/Can It Improve Sperm Yield? J. Clin. Med. 2021, 10, 3667. https:// doi.org/10.3390/jcm10163667

Academic Editors: Giovanni M. Colpi and Ettore Caroppo

Received: 19 July 2021

Accepted: 11 August 2021

Published: 19 August 2021

Publisher's Note: MDPI stays neutral with regard to jurisdictional claims in published maps and institutional affiliations.

Copyright: (C) 2021 by the authors Licensee MDPI, Basel, Switzerland. This article is an open access article distributed under the terms and conditions of the Creative Commons Attribution (CC BY) license (https:/ / creativecommons.org/licenses/by/ $4.0 /)$.

\begin{abstract}
Intracytoplasmic sperm injection (ICSI) has allowed reproduction options through assisted reproductive technologies (ARTs) for men with no spermatozoa within the ejaculate (azoospermia). In men with non-obstructive azoospermia (NOA), the options for spermatozoa retrieval are testicular sperm extraction (TESE), testicular sperm aspiration (TESA), or micro-surgical sperm extraction (microTESE). At the initial time of spermatozoa removal from the testis, spermatozoa are immobile. Independent of the means of spermatozoa retrieval, the subsequent steps of removing spermatozoa from seminiferous tubules, determining spermatozoa viability, identifying enough spermatozoa for oocyte injections, and isolating viable spermatozoa for injection are currently performed manually by laboratory microscopic dissection and collection. These laboratory techniques are highly laborintensive, with yield unknown, have an unpredictable efficiency and/or success rate, and are subject to inter-laboratory personnel and intra-laboratory variability. Here, we consider the potential utility, benefits, and shortcomings of developing technologies such as motility induction/stimulants, microfluidics, dielectrophoresis, and cell sorting as andrological laboratory add-ons to reduce the technical burdens and variabilities in viable spermatozoa isolation from testicular samples in men with NOA.
\end{abstract}

Keywords: non-obstructive azoospermia; testicular spermatozoa; processing; microfluidics; new technologies

\section{NOA Background}

Clinical infertility is a disease of the reproductive system defined by the failure to achieve a clinical pregnancy after 12 months or more of regularly unprotected sexual intercourse [1]. The worldwide prevalence of clinical infertility is approximately $9 \%$, with $56 \%$ of couples seeking medical interventions [2]. Male factor infertility describes couples in whom the inability to conceive is associated with compromised reproductive function in the male partner. Broadly, this can be due to (1) compromised semen parameters involving semen volume, sperm numbers, motility, morphology, or viability; (2) abnormal sperm function; or (3) normal semen/sperm parameters, yet conditions that prevent sperm deposition in the vagina during intercourse involving male reproductive tract obstructions and/or ejaculatory dysfunction [3]. Males are solely responsible for approximately $20-30 \%$ of these clinical infertility cases and contribute to approximately $50 \%$ of cases overall (male factor and female factor). The absence of sperm in an ejaculate is termed azoospermia and occurs in less than $1 \%$ of the general male population and an estimated $10 \%$ of men with infertility. Azoospemia may be caused by an obstruction of the male reproductive tract, which is termed obstructive azoospermia (OA) and makes up approximately $40 \%$ of azoospermic 
cases [4]. Additionally, azoospermia may be a result of inadequate spermatogenesis in the seminiferous tubules of the testis, which is termed non-obstructive azoospermia (NOA). The introduction of intracytoplasmic sperm injection (ICSI; injection of a single sperm into a single oocyte) revolutionized the treatment of male factor infertility, OA, and NOA [5-7]. NOA is considered the most severe and difficult form of azoospermia to treat with assisted reproductive technologies (ARTs) for at least three primary reasons: (1) the method of gamete retrieval; (2) the variable and unpredictable degree of compromised spermatogenesis and success of spermatozoa retrieval/isolation; (3) the initial non-motile nature of retrieved testicular sperm. In this review, we will not address the pros and cons of gamete retrieval methods (as this is specifically addressed in other manuscripts within this series). However, in men with NOA, the following questions arise: (1) Are there focal sites of spermatogenesis within the testes available for spermatozoa isolation? (2) What is the best method to access these focal sites of spermatogenesis? In early studies, testicular sperm extraction (TESE) was used, whereby a single-site testicular biopsy was performed in attempting spermatozoa isolation [8-10]. A retrospective review of first-TESE in NOA from 1994 to 2009 (714 cycles) demonstrated $41 \%$ success of spermatozoa retrieval [11]. A modified approach to TESE is testicular sperm aspiration (TESA), which involves the placement of a needle (often a butterfly needle) with negative pressure into the testis, aspiration of fluid and tissue, and movement into multiple regions of the testis without removal from the testes, to "sample" fluid and tissue from numerous focal areas [12]. Subsequent studies using TESA reported variance in spermatozoa retrieval success ranging from 59\% [13] to 54\% [14]. In contrast to TESE and TESA, microTESE is another form of spermatozoa isolation in NOA. This procedure involves a urologist/surgeon bisecting the testis and using surgical microscopy and 15-20× magnification to identify and isolate dilated/plump seminiferous tubules. Though this surgical procedure is considered more invasive than TESE and TESA, it is a regionally selective biopsy of visualized and isolated seminiferous tubules-resulting in less tissue removal and the ability for spermatozoa identification from isolated tubules to be confirmed by an andrologist in the surgical suite. MicroTESE-isolated seminiferous tubules are subsequently placed into $37^{\circ} \mathrm{C}$ processing media and transported to the andrology laboratory, where they are manually dissected under microscope observation. Ramasamy and colleagues [15] demonstrated that the success of spermatozoa retrieval by microTESE diminished with greater operative time, yet overall was successful in $52 \%$ of cases. The success of spermatozoa isolation from microTESE-isolated seminiferous tubules was shown to be highest in cases of dilated / plump tubule selective biopsy (90\%) versus non-dilated tubule removal (7\%) [16].

\section{Current Laboratory Techniques for Spermatozoa Isolation from NOA Testicular Samples}

Independent of the process used to collect testicular tissue/seminiferous tubules (TESE, TESA, or microTESE), the first steps in the andrology laboratory are to isolate and evaluate seminiferous tubules for the presence of active spermatogenesis (dilated/plump) or lack of spermatogenesis (not dilated/skinny/transparent; Figure 1A). Compared to TESA samples, the amount of testicular somatic or connective tissue is higher in TESE samples, which can make this process of manual seminiferous tubule isolation more difficult. TESA samples tend to yield individualized seminiferous tubules that resemble "unraveled yarn" in the collection media/tube. Within the laboratory, both TESE and TESA samples can require mincing in $37^{\circ} \mathrm{C}$ processing media (simple HEPES-buffered media such as human tubule fluid (HTF)-HEPES + protein (human serum albumin (HSA)) to: (1) release the seminiferous tubules from connective tissue; (2) reduce the size of individualized seminiferous tubules; (3) produce clean-cut edges to seminiferous tubules that will facilitate collection of tubule contents. Mincing can be performed on a dissecting microscope in a drop of processing media, with tissue placed on a Petri dish with tweezers and a scalpel. This manual mincing method is useful for seminiferous tubule isolation from TESE samples. One can use a similar manual method for TESA samples or use tuberculin syringe/26-27-gauge needles to cut tubules into manageable sizes. Due to the surgical and 
selective nature of seminiferous tubule isolation in micro-TESE, the tubules are already isolated in a truncated and pure state and usually do not require laboratory tubule isolation and mincing.

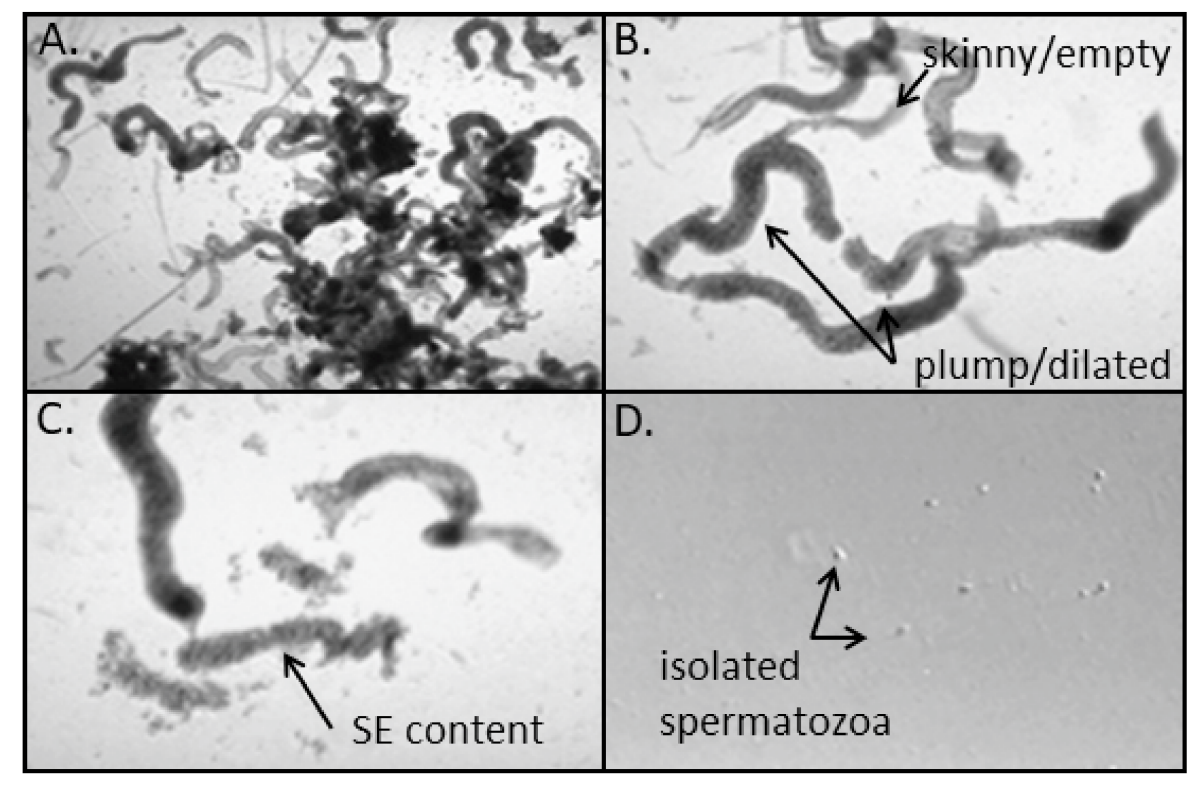

Figure 1. Composite micrographs of laboratory manual processing of testicular aspirate for spermatozoa isolation. (A) Minced seminiferous tubules (ST) in processing media. (B) Isolated truncated ST with indication of plump/dilated ST with presumed active spermatogenesis and skinny/empty ST (also transparent) with presumed absence of spermatogenesis. (C) Seminiferous tubules with one ST processed with tuberculin syringe and needles to squeeze out seminiferous epithelium (SE). (D) Following pulled glass pipet dispersion of SE into single cells, the isolation of non-motile testicular spermatozoa. Magnifications: (A) $-100 \times,($ B,$C)-200 \times,(D)-400 \times$.

Once the individualized dilated/plump tubules are isolated and truncated, they can be moved into a clean drop of $37^{\circ} \mathrm{C}$ processing media (Figure 1B) for further manual processing. At this point, under microscopic observation, a pair of tuberculin syringe/2627-gauge needles can be used to squeeze the seminiferous tubule contents out of each short dilated/plump tubule segment (Figure 1C). This results in seminiferous tubule content that can be aspirated easily into a small-bore $(\sim 15-20 \mu \mathrm{m}$ inner diameter) flame-pulled glass pipet. This allows one to expel the seminiferous tubule contents into a separate fresh drop of $37^{\circ} \mathrm{C}$ processing media as a single-cell suspension, which will contain germ cells of varying degrees of development, supportive cells, and-hopefully-mature spermatozoa (Figure 1D). These testicular-isolated spermatozoa will likely be non-motile; this is especially observed in samples from NOA men [17].

The culture time and conditions have been evaluated for both OA and NOA spermatozoa samples, demonstrating that $24-48 \mathrm{~h}$ culture of testicular spermatozoa in complex media (Ham's F10 + albumin) can benefit spermatozoa maturation and motility induction [18-20]. These maturation conditions can be tested on individuals having testicular spermatozoa retrieval in a diagnostic manner, prior to a therapeutic procedure coordinated with egg retrieval. These "diagnostic" testicular spermatozoa retrievals, maturation/motility initiation, and cryopreservation of isolated "rare" spermatozoa [21-23] can be quite successful and have been nicely reviewed and critiqued [24].

The above-described laboratory procedure of spermatozoa isolation from testicular samples relies primarily on manual, mechanical, microscopic processing and can be quite labor- and time-intensive. There are numerous limitations to the current mechanical method of spermatozoa isolation from testicular samples that need to be addressed. The success and efficiency of spermatozoa isolation are influenced by human experience, examiner fatigue, and the slight procedural variations used to yield single-cell suspensions and visualize 
individual spermatozoa. These laboratory microscopic mechanical procedures can take 2-12 h, depending on testicular sample purity and volume, number of spermatozoa, volumes of media used for procedures, and laboratory personnel experience. As time spent searching for spermatozoa increases, the success of spermatozoa isolation decreases, which can impact subsequent pregnancy rates [15]. Cases with spermatozoa isolation taking $<2 \mathrm{~h}$ had significantly higher pregnancy rates $(89 \%)$ compared to cases taking $>4 \mathrm{~h}(37 \%)$. There have been numerous reports of using enzymatic treatment of testicular samples to aid the recovery of testicular spermatozoa [25-27]; however, its advantages are debated. These enzymatic techniques usually use collagenase type IA or IV to digest the collagen within the basement membrane and extracellular matrix within seminiferous tubules. However, these collagenases have been demonstrated to digest cell surface proteins [28] that may have influence on downstream sperm function in fertilization, pronuclear formation, and embryo development. Additionally, enzymatic methods incorporate centrifugation, which, as discussed below, can have a detrimental impact on spermatozoa DNA integrity. Before discussion of the potential future of microfluidics for spermatozoa isolation from testicular samples of men with NOA, we need to acknowledge that achieving a level of singlecell suspension (as discussed above) will still be required; thus, a significant amount of mechanical and manual processing is still required.

\section{Microfluidics and Potential Use in Spermatozoa Isolation from NOA Testicular Samples}

Microfluidics is defined as a multidisciplinary field of study and design whereby fluid behaviors are accurately controlled and manipulated with small-scale geometric constraints that yield dominance of surface forces over volumetric forces. While past procedures in the ART laboratory have been successful, they have been more macroscale approaches to microscale cellular biological events [29]. Integration of microfluidics into the ART laboratory has at least four foreseeable advantages: (1) allowing precisely controlled fluidic gamete/embryo manipulations; (2) providing biomimetic environments for culture; (3) facilitating microscale genetic and molecular bioassays; (4) enabling miniaturization and automation. The basic utility and advantages of individual microfluidic devices for isolation of motile spermatozoa have been studied and reported over the last two decades. These can generally be categorized as microfluidic means of motile sperm isolation by three similar but slightly discrete biophysical means.

First, motile sperm can be enriched by using a microfluidic-generated laminar flow and sperm motility-enabled crossing of the meniscus or interstream line formed by the laminar flow [30,31]. These devices allow a separation of motile spermatozoa from seminal plasma, non-motile sperm, dead cells, and debris without centrifugation or resulting potential lethal and sublethal spermatozoa damage. The technical parameters of the device were designed to optimize the isolation of motile human spermatozoa with the inflow channel (semen; $100 \mu \mathrm{m} \times 50 \mu \mathrm{m}$; width $\times$ depth), inflow channel (media; $300 \mu \mathrm{m} \times 50 \mu \mathrm{m}$ ), common midchannel (laminar flow; $500 \mu \mathrm{m} \times 50 \mu \mathrm{m} \times 100 \mathrm{~mm}$ length). Centrifugation can negatively influence sperm motility [32], mitochondrial function [33], intact acrosomal status [33], and DNA integrity [34]. Using the microfluidic laminar flow and inertia spermatozoa isolation, it was demonstrated that isolated motile spermatozoa had significantly less DNA damage compared to processing sperm with centrifugation, density gradient and centrifugation, and swim-up of overlaid semen [35-37]. Using a microfluidic device without laminar flow but with microchannel hydrodynamic constrain to isolate motile sperm and the sperm chromatin dispersion assay, which detects primarily single-strand DNA breaks, Quinn and colleagues [38] demonstrated significantly reduced DNA fragmentation index (DFI) in microfluidic isolated motile sperm (median: 0\%; intraquartile ranges (IQR): 0-2.4) compared to motile sperm isolated with density-gradient centrifugation with swim-up (median-6\%; intraquartile ranges (IQR): 3-11.5).

The second microfluidic method for motile sperm isolation involves multiple narrow channels and sperm inertia [39]. These microfluidic devices incorporate a radial array of hundreds of microchannels, with motile sperm swimming from the inlet to the outlets 
away from dead cells, debris, and seminal plasma—resulting in a highly motile population of sperm, again with reduced DNA damage compared to other conventional centrifugationbased semen-processing methods. Recently, these investigators have demonstrated the potential practical use of this design for human sperm isolation for clinical intracytoplasmic sperm injection [40].

Third, Wu and coworkers [41] have developed a microfluidic device that is able to generate an impeding flow field for isolating human motile sperm in a high-throughput manner. While a highly motile population of sperm is isolated in this device, the influence on sperm DNA integrity is unknown; yet, in theory, one would expect reduced processing-induced DNA fragmentation as demonstrated by the other microfluidic methods mentioned above. It is important to appreciate that these microfluidic devices do not directly improve sperm DNA integrity, but they do allow isolation of motile sperm - whereas raw samples have both motile (live) and non-motile (many times dead and DNA fragmented) - without processing-induced DNA damage. Finally, it is important to recognize that all of the above microfluidic devices and methods rely on spermatozoa motility for isolation. As mentioned earlier, testicular spermatozoa at the initial time of retrieval are predominantly non-motile; thus, other creative microfluidic methods or combinations of methods need to be considered in non-motile spermatozoa isolation from NOA testicular samples.

As mentioned above, microfluidics can circumvent centrifugation and deleterious influence on spermatozoa form and function experienced in conventional sperm processing. If one is using enzymatic processing of testicular samples to yield spermatozoa, then centrifugation can be part of the process. However, manual/mechanical processing does not necessarily entail centrifugation. An advantage of microfluidics isolation of spermatozoa from NOA testicular samples compared to other developing methods (magneticactivated cell sorting (MACS) and fluorescence-activated cell sorting (FACS)-reviewed in Mangum et al., 2020 [42]) is the ability to isolate testicular spermatozoa without biochemical fluorescent or bead labeling of cells [43], which presents safety issues that are yet to be fully evaluated in gametes, fertilization, and offspring health [44]. Magnum and colleagues very nicely have provided a summary table of the advantages and disadvantages of these developing technologies. There are additional microfluidic approaches with potential for isolating non-motile testicular spermatozoa that have been proposed or proof-of-concept tested in animal models, such as combined microfluidics and dielectrophoresis cell sorting [45] and pinched flow fractionation [46,47]. Whether these microfluidic approaches and add-ons will be useful and/or beneficial in isolation of non-motile spermatozoa from human testicular samples of NOA men remains to be demonstrated.

\section{Spiral Microfluidics, Inertial Separation, and Cell Size}

As testicular resident spermatozoa are largely non-motile, the use of microfluidic laminar flow for isolation is not useful. Son and colleagues [48] demonstrated an ingenious and novel application of spiral microfluidics to effectively and efficiently separate non-motile spermatozoa (or beads of similar size) from non-motile cells of differing size. This spiral inertial microfluidic device yields separation of particles or cells based on size and shape. Spiral microchannel dimensions were calculated with specific consideration in relation to the cellular constituents of a single-cell suspension of a human testicular sample (spermatozoa, white blood cells (WBCs), and germ cells of a more immature state). This prototype spiral microfluidic device had a single inlet and multiple outlets to separate particles/cells at their equilibrium positions as they exit the device. Calculations were performed considering the differing cell sizes, various flow rates, and best conditions for cell focusing (microchannel height- $50 \mu \mathrm{m}$, microchannel width $-150 \mu \mathrm{m}$, space between microchannels-310 $\mu \mathrm{m}$, initial radius $-700 \mu \mathrm{m}$, and final radius- $899 \mu \mathrm{m}$ ). The authors were able to demonstrate separation and isolation of spermatozoa from WBCs. More recently, Vasilescu and coworkers [49] used a similar spiral microchannel device produced by $3 \mathrm{D}$ printing to demonstrate rapid spermatozoa recovery from heterogeneous cell suspension of spermatozoa, WBCs, red blood cells, epithelial cells, and leukemic cancer 
cells. This study demonstrated rapid (5 min) separation of spermatozoa from other cell types and, very importantly, that this spiral microfluidic processing had no detrimental influence on spermatozoa viability, morphology, or DNA integrity. Collectively, these are exciting findings in the quest for future means of isolating immobile spermatozoa from testicular samples, yet there are some issues that remain uninvestigated and require testing. First, does spermatozoa shape/size asymmetry impact isolation efficiency? Second, while most testicular spermatozoa are non-motile, some testicular sperm can exhibit a form of motility termed "twitching" - how that might impact spiral microfluidic separation and focus isolation remains to be determined. This gives rise to a secondary issue of the need for determining the viability of spiral microfluidic testicular non-motile sperm post-isolation prior to use in ICSI. However, future combinations of spiral inertial microfluidic testicular spermatozoa isolation with a short culture period to induce maturation/some motility [20] or a non-terminal viability test, such as the hypo-osmotic swelling test of spermatozoa membrane integrity [50], may aid in addressing this issue.

\section{Practical and Future Considerations of Using Microfluidics in Spermatozoa Isolation from NOA Testicular Samples}

When initially considering the use of microfluidic applications with existing methods of gamete isolation, in vitro fertilization, embryo culture, gamete/embryo analysis, and/or cryopreservation, we need to first examine the practical shortcomings of the existing techniques, the potential benefits of incorporating microfluidics, and the potential hurdles that this incorporation of microfluidics may have in individual ART procedures. This leads to the practical question of why one might use microfluidics for non-motile spermatozoa isolation from retrieved NOA testicular samples. At a basic level, use of microfluidics would be justified if it does: (1) something we cannot do today; (2) something we do today, but is more efficient or provides a better sample; (3) something we do today, but is less expensive or requires less work, supplies, or personnel effort; (4) something we do today, as well as reduces intra-laboratory personnel and/or inter-laboratory variability; or (5) something we do today, but facilitates future automation and associated benefits [51]. While current methodologies of spermatozoa isolation from NOA testicular samples are manually burdensome and tedious, they do work on most occasions. Whether microfluidics will reduce the cases of "no spermatozoa found for ICSI", increase efficiency, and/or produce a better sample in relation to fertilization rates, embryo development, and livebirth rates remains to be demonstrated. Use of microfluidics to isolate sperm from testicular samples will not become less expensive unless the personnel workload is significantly reduced. This could be the case in the future; however, it is important to recognize that most of the burdensome and tedious manual work in processing testicular samples is in producing a single-cell suspension, which is still needed for current microfluidic application to non-motile spermatozoa isolation from testicular samples. This brings up the potential hurdle of microfluidic application to non-motile spermatozoa isolation-specifically, the lack of microchannel functionality and/or clogging that can and will occur if input samples are not in a single-cell suspension. Notwithstanding the above discussion, the potential use of microfluidics in isolating non-motile spermatozoa from NOA testicular samples should continue to be investigated in rigorous and practical ways. Integration of multiple technologies - existing and of the future-will likely facilitate the use of microfluidics for improving success, reducing technical signatures and variation, and providing bridges over current limitations. Potential examples include combined spiral microfluidics $[48,49]$ with subsequent short-term culture to assess viability/motility [20] and Raman spectroscopy to non-invasively interrogate sperm DNA integrity $[52,53]$.

Author Contributions: Conceptualization, G.D.S., C.C., D.A.O.; Resources, G.D.S.; writing-original, G.D.S.; writing-review, C.C. and D.A.O. All authors have read and agreed to the published version of the manuscript. 
Funding: Work in our laboratories on microfluidics for gamete/embryo biology have been supported by National Research Initiative Competitive Grant from the USDA National Institutes of Food and Agriculture (2005-35203-16148), the Coulter Foundation, and the University of Michigan Reproductive Science Program Collaborative Pilot Grant Program. The APC was funded by the University of Michigan Reproductive Sciences Program Collaborative Pilot Grant to GDS.

Acknowledgments: We would like to thank Sarah Block for her editorial comments. We would also like to acknowledge the scientific contributions of many in microfluidics and andrology that unfortunately have not been referenced in this review due to content and size constraints.

Conflicts of Interest: The authors declare no conflict of interest.

\section{References}

1. Zegers-Hochschild, F.; Adamson, G.D.; de Mouzon, J.; Ishihara, O.; Mansour, R.; Nygren, K.; Sullivan, E.; Vanderpoel, S.; International Committee for Monitoring Assisted Reproductive Technology; World Health Organization. International Committee for Monitoring Assisted Reproductive Technology (ICMART) and the World Health Organization (WHO) revised glossary of ART terminology, 2009. Fertil. Steril. 2009, 92, 1520-1524. [CrossRef] [PubMed]

2. Boivin, J.; Bunting, L.; Collins, J.A.; Nygren, K.G. International estimates of infertility prevalence and treatment-seeking: Potential need and demand for infertility medical care. Hum. Reprod. 2007, 22, 1506-1512. [CrossRef] [PubMed]

3. Schlegel, P.N.; Girardi, S.K. Clinical review 87: In vitro fertilization for male factor infertility. J. Clin. Endocrinol. Metab. 1997, 82, 709-716. [CrossRef]

4. Jarow, J.P.; Espeland, M.A.; Lipshultz, L.I. Evaluation of the azoospermic patient. J. Urol. 1989, 142, 62-65. [CrossRef]

5. Palermo, G.; Joris, H.; Devroey, P.; Van Steirteghem, A.C. Pregnancies after intracytoplasmic injection of single spermatozoon into an oocyte. Lancet 1992, 340, 17-18. [CrossRef]

6. Schoysman, R.; Vanderzwalmen, P.; Nijs, M.; Segal, L.; Segal-Bertin, G.; Geerts, L.; van Roosendaal, E.; Schoysman, D. Pregnancy after fertilisation with human testicular spermatozoa. Lancet 1993, 342, 1237. [CrossRef]

7. Devroey, P.; Liu, J.; Nagy, Z.; Goossens, A.; Tournaye, H.; Camus, M.; Van Steirteghem, A.; Silber, S. Pregnancies after testicular sperm extraction and intracytoplasmic sperm injection in non-obstructive azoospermia. Hum. Reprod. 1995, 10, 1457-1460. [CrossRef]

8. Devroey, P.; Liu, J.; Nagy, Z.; Tournaye, H.; Silber, S.J.; Van Steirteghem, A.C. Normal fertilization of human oocytes after testicular sperm extraction and intracytoplasmic sperm injection. Fertil. Steril. 1994, 62, 639-641. [CrossRef]

9. Silber, S.J.; van Steirteghem, A.; Nagy, Z.; Liu, J.; Tournaye, H.; Devroey, P. Normal pregnancies resulting from testicular sperm extraction and intracytoplasmic sperm injection for azoospermia due to maturation arrest. Fertil. Steril. 1996, 66, 110-117. [CrossRef]

10. Tournaye, H.; Camus, M.; Vandervorst, M.; Nagy, Z.; Joris, H.; Van Steirteghem, A.; Devroey, P. Surgical sperm retrieval for intracytoplasmic sperm injection. Int. J. Androl. 1997, 20 (Suppl. 3), 69-73.

11. Vloeberghs, V.; Verheyen, G.; Haentjens, P.; Goossens, A.; Polyzos, N.P.; Tournaye, H. How successful is TESE-ICSI in couples with non-obstructive azoospermia? Hum. Reprod. 2015, 30, 1790-1796. [CrossRef]

12. Lewin, A.; Weiss, D.B.; Friedler, S.; Ben-Shachar, I.; Porat-Katz, A.; Meirow, D.; Schenker, J.G.; Safran, A. Delivery following intracytoplasmic injection of mature sperm cells recovered by testicular fine needle aspiration in a case of hypergonadotropic azoospermia due to maturation arrest. Hum. Reprod. 1996, 11, 769-771. [CrossRef] [PubMed]

13. Lewin, A.; Reubinoff, B.; Porat-Katz, A.; Weiss, D.; Eisenberg, V.; Arbel, R.; Bar-el, H.; Safran, A. Testicular fine needle aspiration: The alternative method for sperm retrieval in non-obstructive azoospermia. Hum. Reprod. 1999, 14, 1785-1790. [CrossRef]

14. Khadra, A.A.; Abdulhadi, I.; Ghunain, S.; Kilani, Z. Efficiency of percutaneous testicular sperm aspiration as a mode of sperm collection for intracytoplasmic sperm injection in nonobstructive azoospermia. J. Urol. 2003, 169, 603-605. [CrossRef]

15. Ramasamy, R.; Fisher, E.S.; Ricci, J.A.; Leung, R.A.; Schlegel, P.N. Duration of microdissection testicular sperm extraction procedures: Relationship to sperm retrieval success. J. Urol. 2011, 185, 1394-1397. [CrossRef] [PubMed]

16. Caroppo, E.; Colpi, E.M.; Gazzano, G.; Vaccalluzzo, L.; Piatti, E.; D’Amato, G.; Colpi, G.M. The seminiferous tubule caliber pattern as evaluated at high magnification during microdissection testicular sperm extraction predicts sperm retrieval in patients with non-obstructive azoospermia. Andrology 2019, 7, 8-14. [CrossRef] [PubMed]

17. Tabbara, S.O.; Covell, J.L.; Abbitt, P.L. Diagnosis of endometriosis by fine-needle aspiration cytology. Diagn. Cytopathol. 1991, 7, 606-610. [CrossRef] [PubMed]

18. Zhu, J.; Meniru, G.I.; Craft, I. In vitro maturation of human testicular sperm in patients with azoospermia. J. Assist. Reprod. Genet. 1997, 14, 361-363. [CrossRef]

19. Wu, B.; Wong, D.; Lu, S.; Dickstein, S.; Silva, M.; Gelety, T.J. Optimal use of fresh and frozen-thawed testicular sperm for intracytoplasmic sperm injection in azoospermic patients. J. Assist. Reprod. Genet. 2005, 22, 389-394. [CrossRef]

20. Morris, D.S.; Dunn, R.L.; Schuster, T.G.; Ohl, D.A.; Smith, G.D. Ideal culture time for improvement in sperm motility from testicular sperm aspirates of men with azoospermia. J. Urol. 2007, 178, 2087-2091; discussion 2091. [CrossRef]

21. Schuster, T.G.; Keller, L.M.; Dunn, R.L.; Ohl, D.A.; Smith, G.D. Ultra-rapid freezing of very low numbers of sperm using cryoloops. Hum. Reprod. 2003, 18, 788-795. [CrossRef] 
22. Desai, N.; Goldberg, J.; Austin, C.; Sabanegh, E.; Falcone, T. Cryopreservation of individually selected sperm: Methodology and case report of a clinical pregnancy. J. Assist. Reprod. Genet. 2012, 29, 375-379. [CrossRef]

23. Kathrins, M.; Abhyankar, N.; Shoshany, O.; Liebermann, J.; Uhler, M.; Prins, G.; Niederberger, C. Post-thaw recovery of rare or very low concentrations of cryopreserved human sperm. Fertil. Steril. 2017, 107, 1300-1304. [CrossRef] [PubMed]

24. Verheyen, G.; Vernaeve, V.; Van Landuyt, L.; Tournaye, H.; Devroey, P.; Van Steirteghem, A. Should diagnostic testicular sperm retrieval followed by cryopreservation for later ICSI be the procedure of choice for all patients with non-obstructive azoospermia? Hum. Reprod. 2004, 19, 2822-2830. [CrossRef] [PubMed]

25. Crabbe, E.; Verheyen, G.; Silber, S.; Tournaye, H.; Van de Velde, H.; Goossens, A.; Van Steirteghem, A. Enzymatic digestion of testicular tissue may rescue the intracytoplasmic sperm injection cycle in some patients with non-obstructive azoospermia. Hum. Reprod. 1998, 13, 2791-2796. [CrossRef] [PubMed]

26. Baukloh, V.; German Society for Human Reproductive, B. Retrospective multicentre study on mechanical and enzymatic preparation of fresh and cryopreserved testicular biopsies. Hum. Reprod. 2002, 17, 1788-1794. [CrossRef]

27. Ramasamy, R.; Reifsnyder, J.E.; Bryson, C.; Zaninovic, N.; Liotta, D.; Cook, C.A.; Hariprashad, J.; Weiss, D.; Neri, Q.; Palermo, G.D.; et al. Role of tissue digestion and extensive sperm search after microdissection testicular sperm extraction. Fertil. Steril. 2011, 96, 299-302. [CrossRef]

28. Taghizadeh, R.R.; Cetrulo, K.J.; Cetrulo, C.L. Collagenase Impacts the Quantity and Quality of Native Mesenchymal Stem/Stromal Cells Derived during Processing of Umbilical Cord Tissue. Cell Transplant. 2018, 27, 181-193. [CrossRef]

29. Smith, G.D.; Takayama, S. Application of microfluidic technologies to human assisted reproduction. Mol. Hum. Reprod. 2017, 23, 257-268. [CrossRef]

30. Cho, B.S.; Schuster, T.G.; Zhu, X.; Chang, D.; Smith, G.D.; Takayama, S. Passively driven integrated microfluidic system for separation of motile sperm. Anal. Chem. 2003, 75, 1671-1675. [CrossRef] [PubMed]

31. Schuster, T.G.; Cho, B.; Keller, L.M.; Takayama, S.; Smith, G.D. Isolation of motile spermatozoa from semen samples using microfluidics. Reprod. Biomed. Online 2003, 7, 75-81. [CrossRef]

32. Matas, C.; Decuadro, G.; Martinez-Miro, S.; Gadea, J. Evaluation of a cushioned method for centrifugation and processing for freezing boar semen. Theriogenology 2007, 67, 1087-1091. [CrossRef]

33. Raad, G.; Bakos, H.W.; Bazzi, M.; Mourad, Y.; Fakih, F.; Shayya, S.; McHantaf, L.; Fakih, C. Differential impact of four sperm preparation techniques on sperm motility, morphology, DNA fragmentation, acrosome status, oxidative stress, and mitochondrial activity: A prospective study. Andrology 2021. [CrossRef]

34. Zini, A.; Finelli, A.; Phang, D.; Jarvi, K. Influence of semen processing technique on human sperm DNA integrity. Urology 2000, 56, 1081-1084. [CrossRef]

35. Schulte, R.T.; Chung, Y.K.; Ohl, D.A.; Takayama, S.; Smith, G.D. Microfluidic sperm sorting device provides a novel method for selecting motile sperm with higher DNA integrity. Fertil. Steril. 2007, 88, S76. [CrossRef]

36. Shirota, K.; Yotsumoto, F.; Itoh, H.; Obama, H.; Hidaka, N.; Nakajima, K.; Miyamoto, S. Separation efficiency of a microfluidic sperm sorter to minimize sperm DNA damage. Fertil. Steril. 2016, 105, 315-321.e1. [CrossRef]

37. Nagata, M.P.B.; Endo, K.; Ogata, K.; Yamanaka, K.; Egashira, J.; Katafuchi, N.; Yamanouchi, T.; Matsuda, H.; Goto, Y.; Sakatani, M.; et al. Live births from artificial insemination of microfluidic-sorted bovine spermatozoa characterized by trajectories correlated with fertility. Proc. Natl. Acad. Sci. USA 2018, 115, E3087-E3096. [CrossRef]

38. Quinn, M.M.; Jalalian, L.; Ribeiro, S.; Ona, K.; Demirci, U.; Cedars, M.I.; Rosen, M.P. Microfluidic sorting selects sperm for clinical use with reduced DNA damage compared to density gradient centrifugation with swim-up in split semen samples. Hum. Reprod. 2018, 33, 1388-1393. [CrossRef] [PubMed]

39. Nosrati, R.; Vollmer, M.; Eamer, L.; San Gabriel, M.C.; Zeidan, K.; Zini, A.; Sinton, D. Rapid selection of sperm with high DNA integrity. Lab Chip 2014, 14, 1142-1150. [CrossRef] [PubMed]

40. Xiao, S.; Riordon, J.; Simchi, M.; Lagunov, A.; Hannam, T.; Jarvi, K.; Nosrati, R.; Sinton, D. FertDish: Microfluidic sperm selection-in-a-dish for intracytoplasmic sperm injection. Lab Chip 2021, 21, 775-783. [CrossRef] [PubMed]

41. Wu, J.K.; Chen, P.C.; Lin, Y.N.; Wang, C.W.; Pan, L.C.; Tseng, F.G. High-throughput flowing upstream sperm sorting in a retarding flow field for human semen analysis. Analyst 2017, 142, 938-944. [CrossRef]

42. Mangum, C.L.; Patel, D.P.; Jafek, A.R.; Samuel, R.; Jenkins, T.G.; Aston, K.I.; Gale, B.K.; Hotaling, J.M. Towards a better testicular sperm extraction: Novel sperm sorting technologies for non-motile sperm extracted by microdissection TESE. Transl. Androl. Urol. 2020, 9, S206-S214. [CrossRef]

43. Gossett, D.R.; Weaver, W.M.; Mach, A.J.; Hur, S.C.; Tse, H.T.; Lee, W.; Amini, H.; Di Carlo, D. Label-free cell separation and sorting in microfluidic systems. Anal. Bioanal. Chem. 2010, 397, 3249-3267. [CrossRef]

44. Said, T.M.; Land, J.A. Effects of advanced selection methods on sperm quality and ART outcome: A systematic review. Hum. Reprod. Update 2011, 17, 719-733. [CrossRef]

45. de Wagenaar, B.; Dekker, S.; de Boer, H.L.; Bomer, J.G.; Olthuis, W.; van den Berg, A.; Segerink, L.I. Towards microfluidic sperm refinement: Impedance-based analysis and sorting of sperm cells. Lab Chip 2016, 16, 1514-1522. [CrossRef] [PubMed]

46. Horsman, K.M.; Barker, S.L.; Ferrance, J.P.; Forrest, K.A.; Koen, K.A.; Landers, J.P. Separation of sperm and epithelial cells in a microfabricated device: Potential application to forensic analysis of sexual assault evidence. Anal. Chem. 2005, 77, 742-749. [CrossRef] [PubMed] 
47. Liu, W.; Chen, W.; Liu, R.; Ou, Y.; Liu, H.; Xie, L.; Lu, Y.; Li, C.; Li, B.; Cheng, J. Separation of sperm and epithelial cells based on the hydrodynamic effect for forensic analysis. Biomicrofluidics 2015, 9, 044127. [CrossRef]

48. Son, J.; Samuel, R.; Gale, B.K.; Carrell, D.T.; Hotaling, J.M. Separation of sperm cells from samples containing high concentrations of white blood cells using a spiral channel. Biomicrofluidics 2017, 11, 054106. [CrossRef] [PubMed]

49. Vasilescu, S.A.; Khorsandi, S.; Ding, L.; Bazaz, S.R.; Nosrati, R.; Gook, D.; Warkiani, M.E. A microfluidic approach to rapid sperm recovery from heterogeneous cell suspensions. Sci. Rep. 2021, 11, 7917. [CrossRef] [PubMed]

50. Casper, R.F.; Meriano, J.S.; Jarvi, K.A.; Cowan, L.; Lucato, M.L. The hypo-osmotic swelling test for selection of viable sperm for intracytoplasmic sperm injection in men with complete asthenozoospermia. Fertil. Steril. 1996, 65, 972-976. [CrossRef]

51. Holland, I.; Davies, J.A. Automation in the Life Science Research Laboratory. Front. Bioeng. Biotechnol. 2020, 8, 571777. [CrossRef] [PubMed]

52. Mallidis, C.; Wistuba, J.; Bleisteiner, B.; Damm, O.S.; Gross, P.; Wubbeling, F.; Fallnich, C.; Burger, M.; Schlatt, S. In situ visualization of damaged DNA in human sperm by Raman microspectroscopy. Hum. Reprod. 2011, 26, 1641-1649. [CrossRef] [PubMed]

53. Da Costa, R.; Amaral, S.; Redmann, K.; Kliesch, S.; Schlatt, S. Spectral features of nuclear DNA in human sperm assessed by Raman Microspectroscopy: Effects of UV-irradiation and hydration. PLoS ONE 2018, 13, e0207786. [CrossRef] [PubMed] 